\title{
Phase Change Material as Energy Material for Cold Storage and its integration in Civil Air Conditioning Systems: material properties and on field application. \\ DE FALCO Marcello ${ }^{1,2, a^{*}}$
}

\author{
${ }^{1}$ Unit of Process Engineering, Faculty of Engineering, University of Rome "Campus Bio-Medico", \\ Via Alvaro del Portillo 21, 00128 Rome, Italy \\ ${ }^{2}$ Upgrading Services S.p.A., via Aulisio 45, 70124 Bari, Italy \\ am.defalco@unicampus.it
}

Keywords: Energy storage, Materials, Air conditioning system, PCM, Heat exchange.

\begin{abstract}
An innovative cold energy storage system, conceived for a civil application and based on the solidification and the fusion of a PCM (Phase Change Material), is presented and assessed. Firstly, a proper active material (phase transition temperature $=5-8^{\circ} \mathrm{C}$, latent heat $>200 \mathrm{~kJ} / \mathrm{kg}$, immiscibility with water, no subcooling) is selected: after a detailed analysis of the PCM state-of-the-art and of the materials properties, the paraffin RT5HC produced by the company Rubitherm is selected. Then, an innovative heat exchanging system, able to speed up the tank charge and discharge, is presented and described. A $5 \mathrm{kWh}$ prototype is tested, demonstrating the capability to be fully loaded at $4-5 \mathrm{~kW}$ in just one hour. By this patented high-power technology and thanks to the high latent heat of the packed PCM allowing to reduce the occupied volume, the storage tank can be integrated in a air conditioning-user system with a "peak shaving" strategy, leading to an optimization of the chiller operation and to an energy saving for civil air conditioning by $20-30 \%$.
\end{abstract}

\section{Introduction}

Cold Thermal Energy Storage (CTES) technologies are considered the best solution to improve Air Conditioning Systems (ACS) efficiency and to reduce the corresponding peak demand [1]. Moreover, the wide diffusion of renewable energy power plants, intrinsically intermittent, and the growing need to plan the energy consumption and to couple it with the production are leading to the development of innovative solutions to store electricity. Among the energy storage technologies, the batteries are the most widespread and used but they suffer of a series of drawbacks, as the high cost and the short durability, making them inappropriate for a massive application in daily charging/discharging cycles.

For an electricity-driven ACS systems, an alternative storage concept can be conceived: instead of storing the electricity input, the cold energy output can be physically stored by solidifying a specific material, called PCM (Phase Change Material), and then released melting the same material. By this way, a series of unparalleled benefits can be achieved:

- ACS operation efficiency can be optimized. Today, the typical compression-driven ACS follows the user requirements, without any optimization strategy. If a storage buffer is installed in series-parallel (refer to Fig. 1), the output power of ACS can be always close to the optimal point (typically $60-70 \%$ of the nominal power) with an overall Energy Efficiency Ratio (EER) enhancement of $20-30 \%$.

- ACS installed power can be reduced. The typical ratio between the peak and the average power of a ACS unit is within the range 3-5, which means that the units are strongly over-dimensioned. Peak demand occurs for just a few hours per year: in hot countries, top $15 \%$ of peak demand occurs for just 24 hours per year, three-quarters of which is required to meet domestic air conditioning. Installing a cold energy storage system, able to supply the peak demands during hottest days and hours, leads to a reduction of power peak requirements, with benefits both for users (reduction of plant fixed costs and bills) and for the electricity network (reduction of summer peaks and overloads). 
- Integrating an appropriate storage system allows to generate an amount of cold energy during the night hours, with higher efficiency (lower wet bulb temperature) and lower cost (reduced specific electricity price).

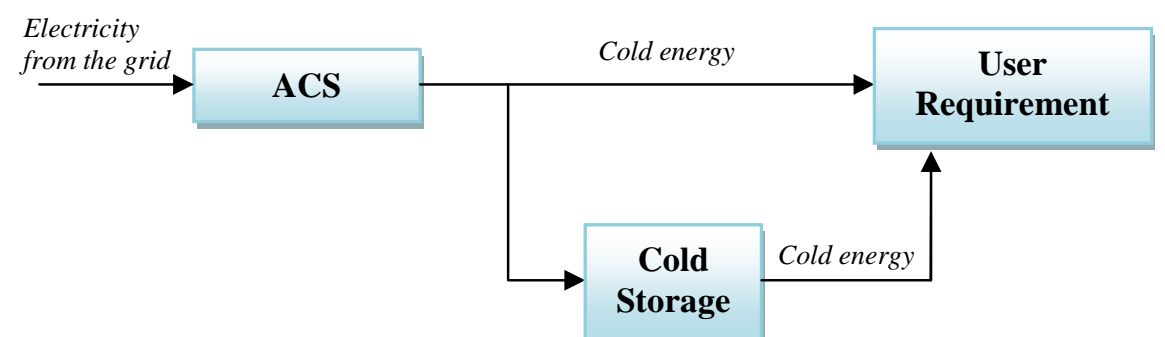

Fig. 1 Integration of a Cold Storage system in a ACS - user plant.

Among the thermal energy storage systems, PCMs are the best solution mainly for the following reasons:

i) PCMs offer a higher value of heat stored per unit volume (up to $50 \mathrm{kWh} / \mathrm{m}^{3}$ ), ranging from 5 to 14 times more than the conventional sensible-heat storage materials;

ii) the energy can be stored and released at constant (or almost constant) temperature, making easier and safer the integration with the ACS;

iii) PCMs are easier to design and manage than thermo-chemical heat storage technologies.

Nevertheless, the main technological drawback of the PCM-based storage systems lies in the dynamics of charge/discharge processes, affected by the heat exchange capability between the PCM and the primary thermal fluid cooled down by the ACS or heated-up by the user. Such an issue can be explained considering a typical tubes-and-shell heat exchanger configuration where liquid PCM is packed inside the shell and the primary water, cooled down by the chiller during charging phase, is fed through the tubes. Clearly, a first layer of solid is formed directly on the heat exchange surface, thus reducing the heat transfer coefficient since the energy transport is through molecular conductivity instead of natural/forced convection. The effect is that the liquid to solid transition is extremely slow and the cold storage unit needs a long time to be charged (low power). This problem makes ineffective the application of the system, since the low charge/discharge power is unable to manage the electricity consumption - user requirements dynamics.

In this paper, an innovative patented solution, conceived for civil applications (residential and tertiary) and able to strongly reduce the storage system charging/discharging kinetics and, consequently, to increase the power, is presented and discussed.

In the following paragraphs, firstly the PCM material selection strategy is discussed, then the storage system is described and its performance assessed.

\section{Material Selection}

For the application in civil environment as cold storage media, a PCM has to assure the following properties:

- high latent heat in the phase change process (> $200 \mathrm{~kJ} / \mathrm{kg}$ );

- the phase change temperature in the range of interest for the specific application $\left(5-8^{\circ} \mathrm{C}\right.$ in the case of storage of cold energy for civil applications);

- phase change temperature as constant as possible or at least in very narrow range (pure components or eutectic alloys);

- reduced subcooling phenomenon (subcooling is the phenomenon for which a lower temperatures than the phase transition temperature has to be reached to begin the phase transition process);

- thermal stability for a large number of cycles;

- low variation of the specific volume in the phase transition;

- low costs; 
- no toxicity, no flammability;

- compatibility with common building materials;

- for the reasons explained in the next paragraph, immiscibility with water.

Generally, PCM are classified in 4 categories [2]:

1. Hydrated salts;

2. Eutectic alloys;

3. Paraffins/Waxes;

4. Fat acids.

Paraffins and waxes are the best compromise among the latent heat of fusion $(150-250 \mathrm{~kJ} / \mathrm{kg})$, the absence of subcooling phenomenon and safety issues, although they are characterized by a low storage density (liquid density $=700-850 \mathrm{~kg} / \mathrm{m}^{3}$ ) [3].

B. Young et al. published a complete database of thermo-physical properties of potential phase change materials for cold storage applications [4]. Imposing a latent heat $>200 \mathrm{~kJ} / \mathrm{kg}$ and a phase transition temperature within the range $5-8^{\circ} \mathrm{C}$, the PCMs which can be applied are:

5. 14-Carbons paraffin, produced and tested in Kun-Shan University [5];

6. n-Tetradecane, tested by Sarier et al [6].

7. RT5HC material, produced and sold by the company Rubitherm [7];

8. organic alloy PCM-0M06P, produced and sold by the company SavENRG [8].

Among them, the only commercial products are the materials 3 and 4 , whose properties are summarized in Table 1.

Table 1. PCM candidates properties comparison.

\begin{tabular}{|l|l|l|}
\hline Property & RT5HC (Rubitherm) & PCM-0M06P (SavENRG) \\
\hline Latent Heat & $240 \mathrm{~kJ} / \mathrm{kg}$ & $260 \mathrm{~kJ} / \mathrm{kg}$ \\
\hline Transition temperature & $5^{\circ} \mathrm{C}$ & $5.5^{\circ} \mathrm{C}$ \\
\hline Constant Temperature? & YES & YES \\
\hline Immiscible with water? & YES & YES \\
\hline Mass per $\mathrm{kWh}$ & $15 \mathrm{~kg} / \mathrm{kWh}$ & $13.8 \mathrm{~kg} / \mathrm{kWh}$ \\
\hline Volume per $\mathrm{kWh}$ & $19 \mathrm{liter} / \mathrm{kWh}$ & $18.8 \mathrm{liter} / \mathrm{kWh}$ \\
\hline
\end{tabular}

Both materials have all the characteristics required for the cold energy storage application in civil environment. In the following, RT5HC has been integrated as the storage media.

\section{Storage System description and Performance Analysis}

To improve the dynamics of storage charging/discharging cycles, an innovative heat exchanging system has been designed, realized and tested. The technology, called ColdPeak and patented [9], is composed by a tank that contains a heterogeneous mixture of distilled water and of the selected PCM material. The two immiscible liquids are layered inside the tank, with the PCM placed in the upper side (its density in liquid phase is $760 \mathrm{~kg} / \mathrm{m}^{3}$ ). A coaxial heat exchanger is immersed in the PCM volume, as shown in Fig. 2. The water available at the bottom of the tank is suctioned by a feed pump and fed to the inner tube of the coaxial heat exchanger (secondary circuit); then, it is fed at the top of the tank by nozzles and drops down for gravity. The external flow in the coil annulus comes from the chillers-users circuit (primary circuit). The PCM solidification during charging phase is uniform inside the PCM volume and the cold transfer from water to PCM occurs by a direct contact of the drops. Moreover, the nozzles jets allow a liquid movement, thus the heat transfer mechanism during the first phase of the solidification process is the forced convection. In addition to the thermal flow exchanged by the water drops and the PCM volume, a second heat exchange contribution is due to the heat transfer through the external wall of the coaxial exchanger. 


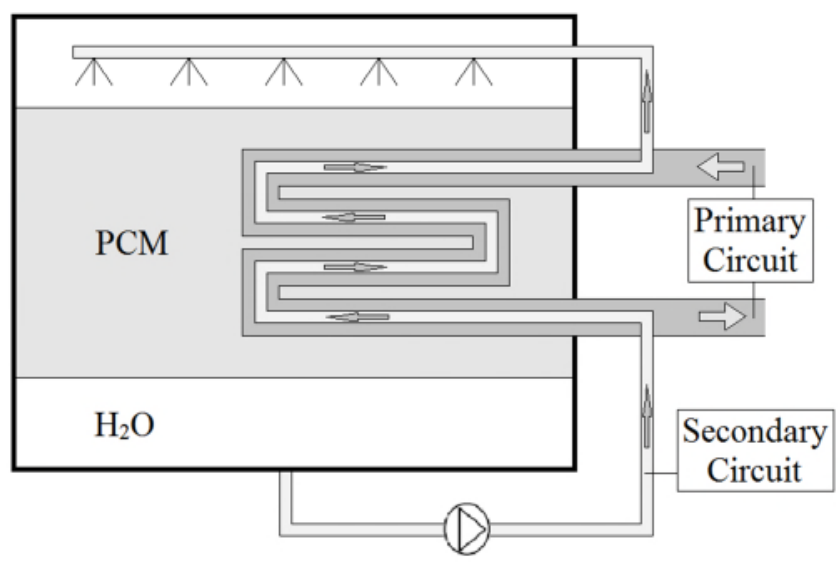

Fig. 2 Cold storage tank layout $[10,11]$.

The storage tank is integrated in a chillers-user system according the layout shown in Fig. 3. The valves system allows the energy tank to work in three different configurations: charge, mixed release and pure release. While charging, the unit is in series with the chillers and the user is excluded from the circuit. All the cooling energy produced by the chillers is stored by the solidification of the PCM. Once the system is charged, the thermal energy stored can be released through the melting of the PCM, using two configurations: pure release and mixed release. In the first one, the users are supplied by the thermal energy released by the tank, while the chiller is turned off. Only a storage system which employs PCM can operate in this configuration while maintaining a nearly-steady state: the operating temperatures in the heat exchanger are constrained in a narrow domain determined by the melting range of the PCM. This allows running the ACS without showing sensible spreads in the inlet/outlet temperatures of the users. In the case of the mixed release configuration, the cold water flow is produced in parallel by both the chillers and the storage unit.

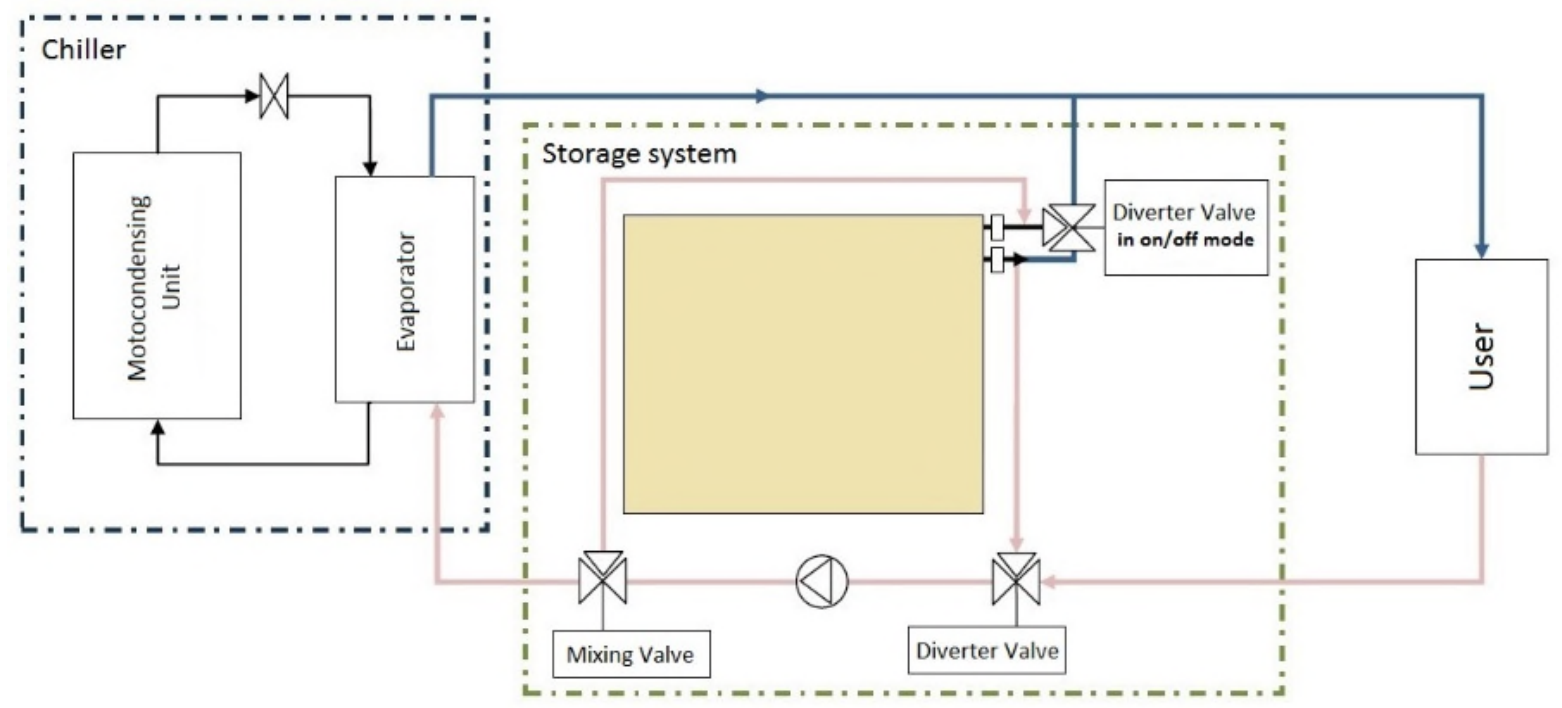

Fig. 3 Plant scheme of the storage unit integrated in a chillers-users air conditioning system [10, 11].

A first $5 \mathrm{kWh}$ prototype has been developed, fabricated, modeled and tested [10, 11]. Fig. 4 shows a typical charging test: the charging power fed by the ACS is constantly within the range 4-5 kW, thus completely solidifying the PCM and, therefore, loading the tank in just one hour thanks to the effective heat exchanging device. 


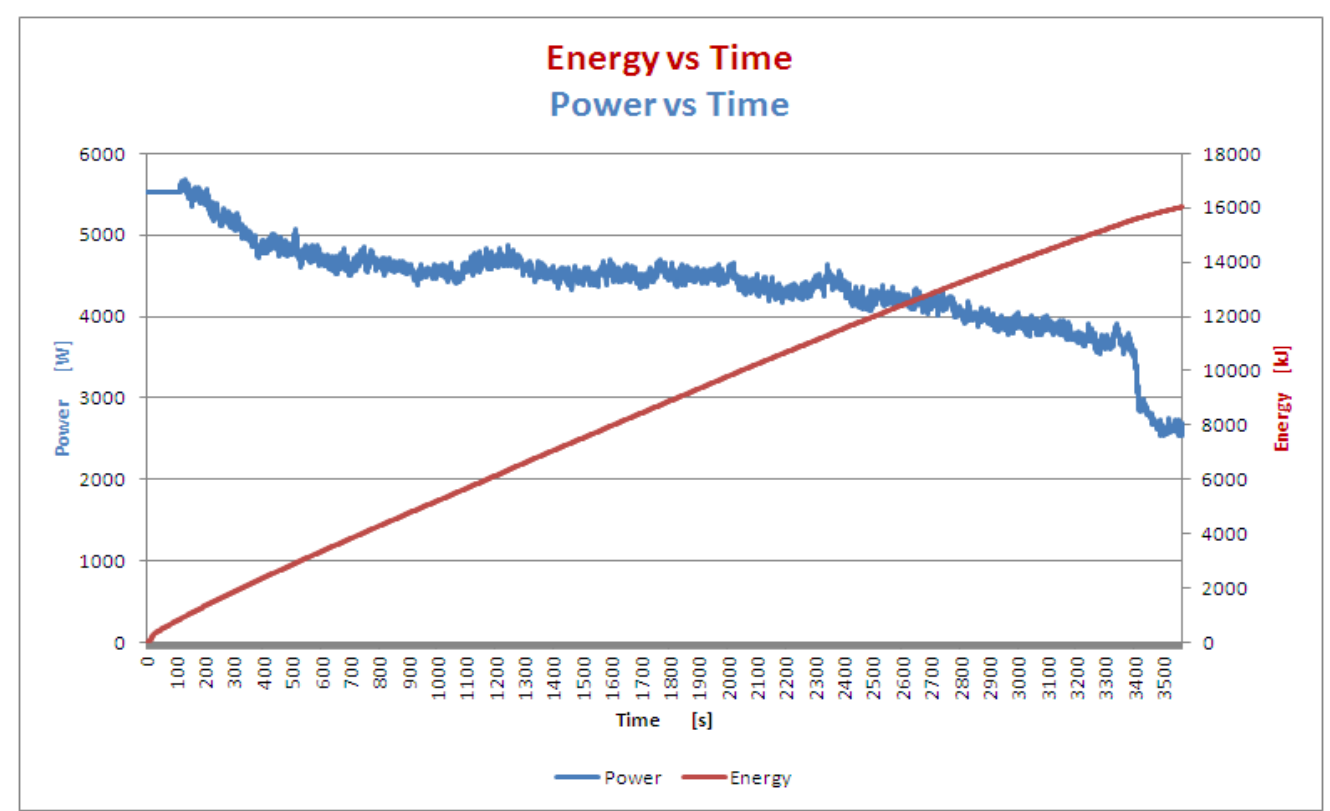

Fig. 4 Energy and Power vs. Time during a charging test of the 5 kWh storage tank.

\section{Conclusions}

An innovative PCM-based cold energy storage tank has been developed and tested. After the selection of a proper storage material (solidification temperature $=5-8^{\circ} \mathrm{C}$, latent heat $>200 \mathrm{~kJ} / \mathrm{kg}$, immiscible with water, no subcooling) among the ones proposed in the literature or sold in the market, a $5 \mathrm{kWh}$ prototype has been design and fulfilled.

The testing phase demonstrates that the innovative heat exchanging system is able to speed up the solidification process of the PCM and to completely charge the tank in 1 hour.

The high-power and compact tank can be integrated in an ACS-user system with a "peak shaving" strategy, allowing to implement an optimization of the chiller operation and leading to an energy saving for civil air conditioning by $20-30 \%$.

\section{Acknowledgement}

The technology presented in this work is patented by the company Upgrading Services S.p.A.. The exclusive of the technology is fully owned by Upgrading Services S.p.A.

This work was carried out within the framework of the project entitled "ColdPeak" and funded by Puglia Region ("PIA - Aiuti ai programmi integrati promossi da PICCOLE IMPRESE ai sensi dell'articolo 27 del Regolamento".

\section{References}

[1] H. Mehling, L. F. Cabeza, Heat and Cold Storage with PCM - An up to date introduction into basics and applications, Springer Edition, 2008.

[2] A. A. Kamble, S. R. Karale, A review-thermal energy storage based dual mode air conditioning system, Int. J. Eng. Res. Appl. 3(2) (2013) 1600-1604.

[3] B. He, V. Martin, F. Setterwall, Phase transition temperature ranges and storage density of paraffin wax phase change materials, Energ. 29(11) (2004) 1785-1804.

[4] B. Young, A. M. Thiele, L. Pilon, Thermophysical properties of phase change materials, 2014, http://www.seas.ucla.edu/ pilon/downloads.htm.

[5] A. Sharma, Review on thermal energy storage with phase change materials and applications, Ren. Sustain. En. Rev. 13(2) (2009) 318-345. 
[6] E. Onder, N. Sarier, E. Cimen, Encapsulation of phase change materials by complex coacervation to improve thermal performances of woven fabrics, Thermochim, Acta 467 (1-2) (2008) 63-72.

[7] http://www.rubitherm.eu/en/index.php/productcategory/organische-pcm-rt.

[8] http://www.rgees.com/documents/TDS_2016/PR6_TDS_OM06P.pdf.

[9] M. De Falco, A. Zaccagnini, Refrigeration, or thermal, energy storage system by Phase Change Materials, PCT/IT2015/000209.

[10] M. De Falco, M. Capocelli, A. Giannattasio, Performance analysis of a innovative PCM-based device for Cold Storage in the Civil Air Conditioning, Energ. Build. 122 (2016) 1-10.

[11]M. De Falco, G. Dose, A. Zaccagnini, PCM-Cold Storage System: an Innovative Technology for Air Conditioning Energy Saving, Chem. Eng. Trans. 43 (2015) 1981-1986. 